Supporting Information for

\title{
The Methoxy-Substituted TQEN Family of Fluorescent Zinc Sensors
}

Yuji Mikata, ${ }^{*, a}$ Motoko Wakamatsu, ${ }^{\text {b }}$ Ayano Kawamura, ${ }^{\mathrm{b}}$ Natsuko Yamanaka, ${ }^{\mathrm{b}}$ Shigenobu Yano, ${ }^{\text {b }}$ Akira Odani, ${ }^{\mathrm{c}}$ Kazuko Morihiro, ${ }^{\mathrm{d}}$ and Satoshi Tamotsu ${ }^{\mathrm{d}}$

${ }^{a}$ KYOUSEI Science Center, ${ }^{b}$ Division of Material Science, and ${ }^{d}$ Department of Biological Sciences, Nara Women's University, Nara 630-8506, Japan and 'Research Center for Materials Science, Nagoya University, Furo-cho, Chikusa-ku, Nagoya, 464-8602, Japan

\section{Experimental}

pH Titrations. $\mathrm{pH}$ Titrations were carried out at $25 \pm 0.05{ }^{\circ} \mathrm{C}$ and $I=0.1 \mathrm{M}(\mathrm{KCl}, 80$ (v/v) \% DMF- $\mathrm{H}_{2} \mathrm{O}$ ) under an Ar atmosphere. $\mathrm{pH}$ values were measured with a Fisher-Scientific Accumet model 15 pH meter equipped with a Beckman 511090 glass electrode and a Beckman 511105 double junction reference electrode. The NIST standard buffers $\left(4.008,7.413,9.008\right.$ at $\left.25{ }^{\circ} \mathrm{C}\right)$ were used for calibration of the $\mathrm{pH}$ meter. For determination of the acid dissociation constants $\mathrm{p} K a, 0.1-0.2 \mathrm{mM}$ ligand solution $\left(80(\mathrm{v} / \mathrm{v}) \%\right.$ DMF- $\left.\mathrm{H}_{2} \mathrm{O} 40 \mathrm{ml}\right)$ containing an excessive amount of $\mathrm{HCl}$ $([\mathrm{HCl}] /[$ ligand $]=7)$ were titrated with standard $0.1 \mathrm{M} \mathrm{KOH}\left(80(\mathrm{v} / \mathrm{v}) \% \mathrm{DMF}_{-} \mathrm{H}_{2} \mathrm{O}\right)$. The stability constants for $\mathrm{LH}_{\mathrm{n}}$ were calculated from the titration data by the leastsquares program SUPERQUAD.

Conversion of $\mathrm{pH}$ meter readings to hydrogen ion concentrations was made by the conversion factor $f=10^{-\mathrm{pH}} /\left[\mathrm{H}^{+}\right]$which was determined by the titration of the system without ligand. $\mathrm{pKw}^{\prime}=13.88$ was obtained .

Binding Affinity Evaluation. Dissociation constants $K_{\mathrm{d}}$ of TQEN, T(MQ)EN, and $\mathrm{T}(\mathrm{TMQ}) \mathrm{EN}$ were determined from the titration data as follows. Considering the zinc ion depletion upon binding, equations (1)-(3) are derived:

$$
\begin{aligned}
& K_{d}=\frac{Z n_{\text {free }} L_{\text {free }}}{Z n_{\text {complex }}} \\
& Z n_{\text {complex }}=\frac{F}{F_{\text {max }}} L_{0} \\
& Z n_{\text {free }}=Z n_{\text {total }}-Z n_{\text {complex }}
\end{aligned}
$$


where $Z n_{\text {free }}$ is the concentration of unbound zinc ion, $L_{\text {free }}$ is the concentration of unbound ligand, $Z n_{\text {complex }}$ is the concentration of Zn-ligand complex, $F$ is the fluorescence change, $F_{\max }$ is the maximum fluorescence change at saturation, $L_{0}$ is the concentration of total ligand added, and $Z n_{\text {total }}$ is the concentration of total zinc ion added. Rearrangement of equations (1)-(3) yields quadratic equation, whose solution is shown below:

$$
F=\frac{F_{\max }\left(L_{0}+Z n_{t o t}+K_{d}-\sqrt{\left(L_{0}+Z n_{t o t}+K_{d}\right)^{2}-4 Z n_{t o t} L_{0}}\right)}{2 L_{0}}
$$

Dissociation constants were calculated from nonlinear regression of the titration data on equation (4) using GraphPad Prizm software version 4.0a for Macintosh, GraphPad Software, Inc., www.graphpad.com.

Fluorescent Quantum Yield. Fluorescent quantum yields of T(MQ)EN and $\mathrm{T}(\mathrm{TMQ}) \mathrm{EN}$ were measured at $25{ }^{\circ} \mathrm{C}$ in $50 \%$ aqueous DMF using quinine in $0.5 \mathrm{M}$ $\mathrm{H}_{2} \mathrm{SO}_{4}(\phi=0.546)$ as a standard. The difference in the refractive indexes between water and 50\% aqueous DMF was not considered.

${ }^{1}$ Gans, P.; Sabatini, A.; Vacca, A. J. Chem. Soc., Daltan Trans. 1985, 1195. 
Table S1. Crystallographic Data for T(MQ)EN and $[\mathrm{Zn}(\mathrm{T}(\mathrm{MQ}) \mathrm{EN})] \cdot\left(\mathrm{ClO}_{4}\right)$

\begin{tabular}{|c|c|c|}
\hline & $\mathrm{T}(\mathrm{MQ}) \mathrm{EN}$ & {$[\mathrm{Zn}(\mathrm{T}(\mathrm{MQ}) \mathrm{EN})] \cdot\left(\mathrm{ClO}_{4}\right)$} \\
\hline Formula & $\mathrm{C}_{46} \mathrm{H}_{44} \mathrm{~N}_{6} \mathrm{O}_{4}$ & $\mathrm{C}_{46} \mathrm{H}_{44} \mathrm{Cl}_{2} \mathrm{~N}_{6} \mathrm{O}_{12} \mathrm{Zn}$ \\
\hline FW & 744.89 & 1009.17 \\
\hline Crystal System & monoclinic & triclinic \\
\hline Space group & $\mathrm{C} 2 / \mathrm{c}$ & $\mathrm{P}-1$ \\
\hline$a, \AA$ & $12.6761(5)$ & $12.355(3)$ \\
\hline$b, \AA$ & $12.7480(5)$ & 13.418(3) \\
\hline$c, \AA$ & $24.1580(11)$ & 13.574(3) \\
\hline$\alpha, \operatorname{deg}$ & 90 & $80.628(6)$ \\
\hline$\beta, \operatorname{deg}$ & $95.677(2)$ & $88.203(7)$ \\
\hline$\gamma$, deg & 90 & $76.681(6)$ \\
\hline$V, \AA^{3}$ & $3884.7(3)$ & 2160.4(9) \\
\hline Z & 4 & 2 \\
\hline$D_{\text {calc }} \mathrm{g} \mathrm{cm}^{-3}$ & 1.274 & 1.551 \\
\hline$\mu, \mathrm{cm}^{-1}$ & 0.083 & 0.766 \\
\hline $2 \theta_{\max }, \mathrm{deg}$ & 57.4 & 55.0 \\
\hline temp, $\mathrm{K}$ & 173 & 173 \\
\hline no. reflns collected & 21033 & 18558 \\
\hline no. reflns used & 5002 & 9475 \\
\hline no. of params & 342 & 605 \\
\hline final R1 $(I>2 \theta(I))$ & 0.052 & 0.054 \\
\hline wR2 (all data) & 0.118 & 0.167 \\
\hline GOF & 1.054 & 1.072 \\
\hline
\end{tabular}

$\mathrm{R} 1=\Sigma|| \mathrm{F}_{\mathrm{o}}|-| \mathrm{F}_{\mathrm{c}} \| / \Sigma\left|\mathrm{F}_{\mathrm{o}}\right| . \quad \mathrm{wR} 2=\left[\Sigma \mathrm{w}\left[\left(\mathrm{F}_{\mathrm{o}}^{2}-\mathrm{F}_{\mathrm{c}}^{2}\right)^{2}\right] / \Sigma\left[\mathrm{w}\left(\mathrm{F}_{\mathrm{o}}^{2}\right)^{2}\right]\right]^{1 / 2}$. 


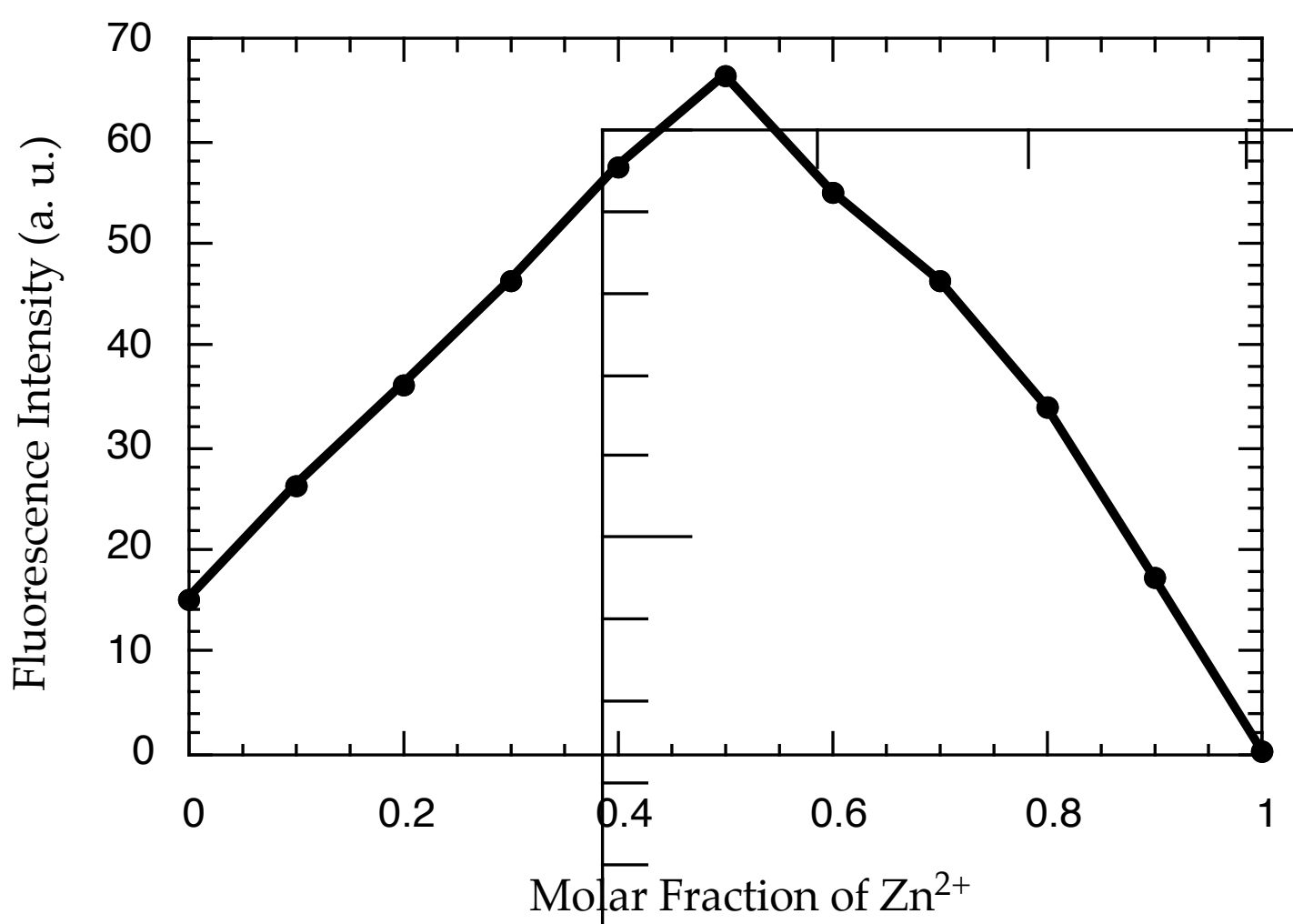

Figure S1. Job's plot for fluorescent intensity of $T(M Q) E N-z i n c$ complex in $\mathrm{DMF} / \mathrm{H}_{2} \mathrm{O}(1: 1)$. The sum of the concentrations of T(MQ)EN and $\mathrm{Zn}^{2+}$ is $34 \mu \mathrm{M}$. 


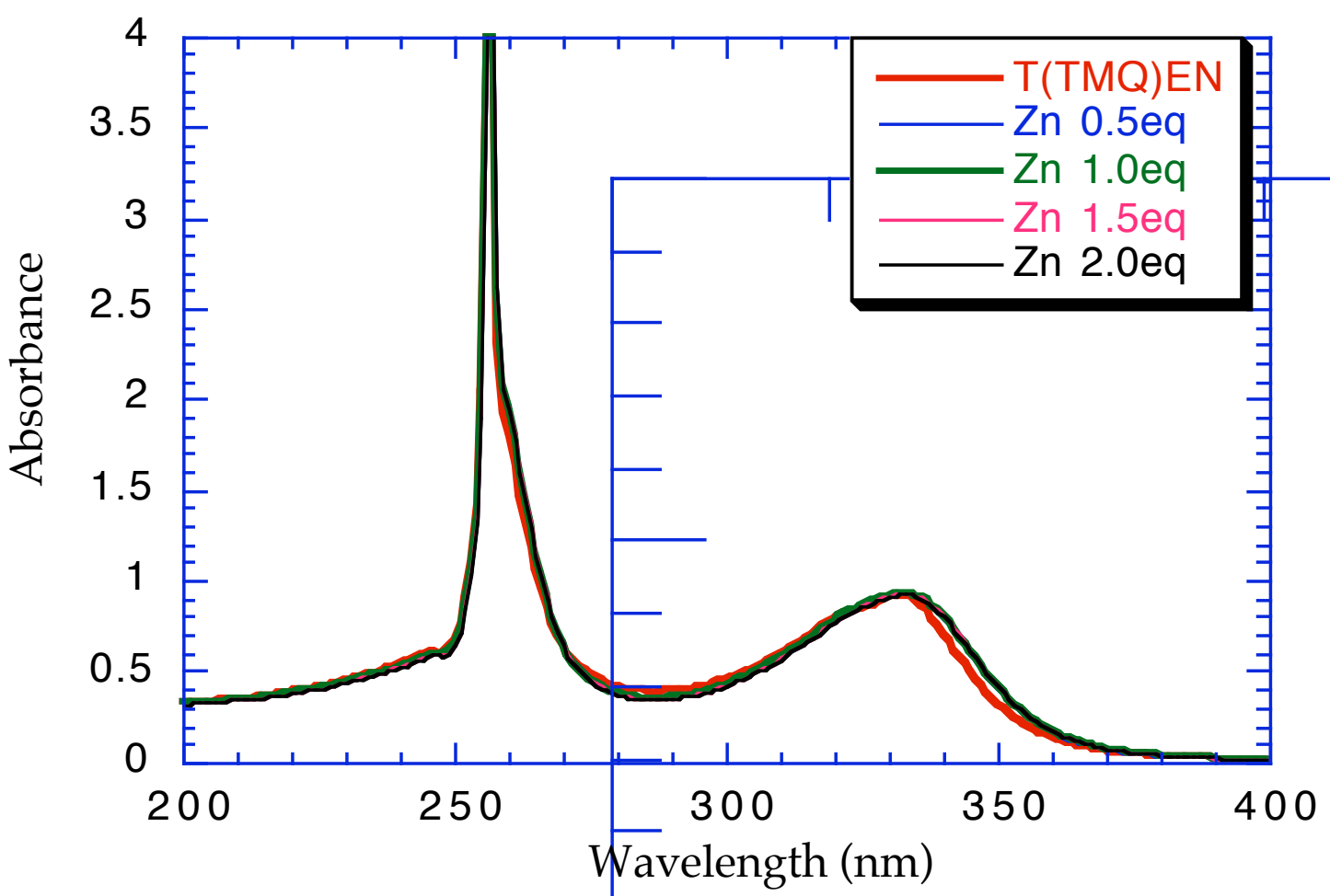

Figure S2. UV-Vis spectra of $34 \mu \mathrm{M} \mathrm{T}(\mathrm{TMQ}) \mathrm{EN}$ in $\mathrm{DMF} / \mathrm{H}_{2} \mathrm{O}(1: 1)$ in the presence of various concentration of $\mathrm{Zn}^{2+}$ ranging from 0 to $68 \mu \mathrm{M}$. 